\title{
Functional Control Synthesis of Single-Phase Low Power Motor Drives
}

\author{
Yu.N. Dementyev ${ }^{1, *}$, N.V. Koyain ${ }^{1}$, A.S. Meshkov ${ }^{2}$ Min Thu Aung ${ }^{2}$, V.I. Susdorf ${ }^{2}$, A. Umurzakova ${ }^{1}$ \\ ${ }^{1}$ Tomsk Polytechnic University, School of Energy \& Power Engineering, av. Lenina, 30, 634050, Tomsk, Russian Federation \\ ${ }^{2}$ Komsomolsk-na-Amure State Technical University, Electric Drive and Automation of Industrial Installations, av. Lenina, 27, \\ 681013, Komsomolsk-na-Amure, Russian Federation
}

\begin{abstract}
In the paper an electric drive system of series-wound universal motor powered by semiconductor converter is considered. The system characteristics and calculation procedure using spectral method of Solodovnikov and aligning procedure are shown. We derived and displayed expressions for two-dimensional non-stationary transfer functions and non-stationary spectral characteristics of output variables of automated control system of single-phase series-wound universal motor powered by semiconductor converter. We also show results of electromagnetic calculation of the electric drive system of series-wound universal motor powered by semiconductor converter for various firing angles $\theta$ of the converter, as well dependences of conduction angle $\omega t$ for varied values of rotational speed $\Omega$ and load torque on the shaft of the motor.
\end{abstract}

Keywords: spectral characteristic, transfer function, quasi-stationary processes, electromagnetic processes, functional relationship.

Received on 31 May 2018, accepted on 08 September 2018, published on 25 October 2018

Copyright (C) 2018 Yu.N. Dementyev et al., licensed to ICST. This is an open access article distributed under the terms of the Creative Commons Attribution licence (http://creativecommons.org/licenses/by/3.0/), which permits unlimited use, distribution and reproduction in any medium so long as the original work is properly cited.

doi: 10.4108/eai.12-9-2018.155861

"Corresponding author. Email:dementev@tpu.ru

\section{Introduction}

The automatic control theory methods based on handling of transfer functions, unit-impulse responses, etc. have advantages over numerical solutions, as they provide for the ability to carry out deeper analysis and perform less design steps. The further development of the automatic control theory enables one to adapt these methods to digital computing systems. The spectral analysis is one of the methods mentioned above that calculates using algebraic algorithms, making it also possible to carry out some analytical operations, greatly reducing computation time. There are no limitations with the degree of differential equations, number and character of variable parameters and number of feedback cycles.

Modern semiconductor devices installed in $\mathrm{AC}$ voltage circuitry or rectified power voltage circuitry [1, 5, 11-13] are presently used for the control of single-phase commutated series-wound motors. When a single-phase commutated motor is operated on such a semiconductor converter, machine operation has a number of issues due to power voltage ripples. Additional losses in windings of copper, magnet core steel, and structural components are caused by the presence of $\mathrm{AC}$ components in armature current and machine magnetic fluxes. Increases in copper losses are related to the rise of effective armature current and significant build-up of copper resistance by current variables. In general, the harmonic composition of the armature current depends on the spectrum of converter output voltage and equivalent resistance of armature circuit for the specific harmonic components [2, 3, 15-18].

\section{Concept headings}

Specific features mentioned above and others actualize the task of research of electromagnetic processes in engine circuits and an identification of the main functional relationships of output characteristics from controlled parameters.

The behavior of motor drive with single-phase commutated series-wound motor is described by the following differential equation system [3, 14, 19-23]: 


$$
\left.\begin{array}{l}
U(t)=R_{d} i(t)+\frac{d \psi(t)}{d t}+k \psi_{M}(t) \Omega(t) ; \\
M(t)-M_{c}(t, \Omega)=J \frac{d \Omega(t)}{d t} ; \\
M(t)=\psi_{M}(t) i(t) ; \\
U(t)=F\left(\theta, \omega, m, \psi_{M}, \psi, t\right),
\end{array}\right\}
$$

where, $U(t)$ - motor power voltage; $i(t)$ - armature current; $R_{d}$ - active resistance of armature circuit; $\Omega(t)$ - shaft rotation frequency; $k$ - proportionality factor of rotating electromotive force; $\psi(t), \psi_{M}(t)$ - full flux linkage and mutual inductance flux linkage; $M(t), M_{c}(t)$ - electromagnetic torque and shaft static resistance torque; $J$ - motor inertia moment; $F(\theta, \omega, m$, $\left.\psi_{M}, \psi, t\right)$-generalized function that simulates converter output voltage; $\theta$-control angle; $\omega$-network angular frequency; $m$ - number of converter phases; $t$ - time.

In order to compose an algorithm for motor analysis as an object of control, provided that input actions and initial conditions have been determined, the equations for twodimensional unstable transfer functions and unstable spectral characteristics of output variables are deducted: motor rotation speed $\Omega(t)$, torque $M(t)$, and armature circuit current $I(t)$. Considering that the output coordinates are described by piecewise smooth, monotone functions, it is reasonable to assign a system of unstable orthonormal trigonometrical functions as a basic one, in order to obtain the most simple equations for spectral characteristics. Given the linear properties of unstable spectral characteristics, derived time functions at non-zero initial conditions and the product of time functions, we deduct the following equations (hereinafter, lower index "c" indicates the spectral characteristic of the appropriate function):

$$
\left.\begin{array}{l}
E_{c}(t)-P_{c c}(t, t) \psi_{c}(t)-R_{d} I_{c}(t)=U_{c}(t)+\psi_{0} \Delta_{c}(t) ; \\
J^{-1} P_{c c}^{-1}(t, t) \Omega_{c}(t)-M_{c}^{c}(t)=J^{-1} \Omega_{0} \Delta_{c}(t)-M_{c}^{c}(t) \Delta_{c}(t) ; \\
E_{c}(t)=k \psi_{c}^{M}(t) \Omega_{c}(t) \\
M_{c}(t)=\psi_{c}^{M}(t) I_{c}(t) \\
U_{c}(t)=A_{c c}(t, t) U_{c}^{0}(t),
\end{array}\right\}
$$

where, $P_{c c}(t, t)$ - two-dimensional unstable transfer function of differentiating section; $A_{c c}(t, t)$ - two-dimensional unstable transfer function of converter represented by variable gain section; $V_{c c c}(t, t)$ - three-dimensional transfer function of multiplier; $\Omega_{c}(t), I_{c}(t), U_{c}(t), E_{c}(t), \psi_{c}(t), \psi_{c}{ }^{M}(t), M_{c}(t), M_{c}{ }^{c}(t)$ unstable spectral characteristics of rotation frequency, current, output voltage of converter, rotating electromotive force, full flux linkage, mutual inductance flux linkage of armature winding and excitation field, electromagnetic torque and shaft resistance torque respectively; $\Omega_{0}, \psi_{0}$-initial conditions; $\Delta_{c}(t)$ - unstable spectral characteristic of delta function; $U_{c}^{0}(t)$ - unstable spectral characteristic of input voltage simulating function; $J$ - motor drive inertia moment at the motor shaft.

In order to develop a multi-dimensional transfer function of the system under research, the output actions and output signals represented by column matrices $g(\tau)$ and $x(\tau)$ have been arranged :

$$
\begin{gathered}
g(t)=\left[\begin{array}{lllll}
U(\tau) & M^{c}(\tau) & t_{0}(\tau) & \Omega_{0} & \psi_{0}
\end{array}\right]^{\mathrm{T}} ; \\
x(t)=\left[\begin{array}{llll}
\Omega(\tau) & M(\tau) & I(\tau)
\end{array}\right]^{\mathrm{T}},
\end{gathered}
$$

where $M^{c}(\tau)$ - static torque on a motor shaft; $\mathrm{t}_{0}$ - initial value of time in the specified cycle.

The matrix of two-dimensional unstable transfer function of the system is as follows:

$$
\Phi(t, t)=\left[\begin{array}{cccc}
\Phi_{11}(t, t) & \Phi_{12}(t, t) & \ldots & \Phi_{1 v}(t, t) \\
\vdots & \vdots & \vdots & \vdots \\
\Phi_{\mu 1}(t, t) & \Phi_{\mu 2}(t, t) & \ldots & \Phi_{\mu v}(t, t)
\end{array}\right],
$$

where $\Phi_{\mu v}(\mathrm{t}, \mathrm{t})$ - transfer functions characterizing $\mu$ output $(\mu$ $=1,2,3)$ and $v$ input $(v=1,2,3,4,5)$ connection.

The above-mentioned functions allow for the building up of a block diagram for the system (fig. 1) [4]. In this case, the operators are replaced by spectral characteristics of signals.

The nonlinearity associated with the relationship of absolute permeability and the current is approximated by the truncated orthonormal series.

Considering the symmetric property of the nonlinearity, the permeability can be defined as follows:

$$
\mu_{j}=a_{1} I+a_{3} I^{3}+a_{5} I^{5}, \quad 0<I<I_{\max } .
$$




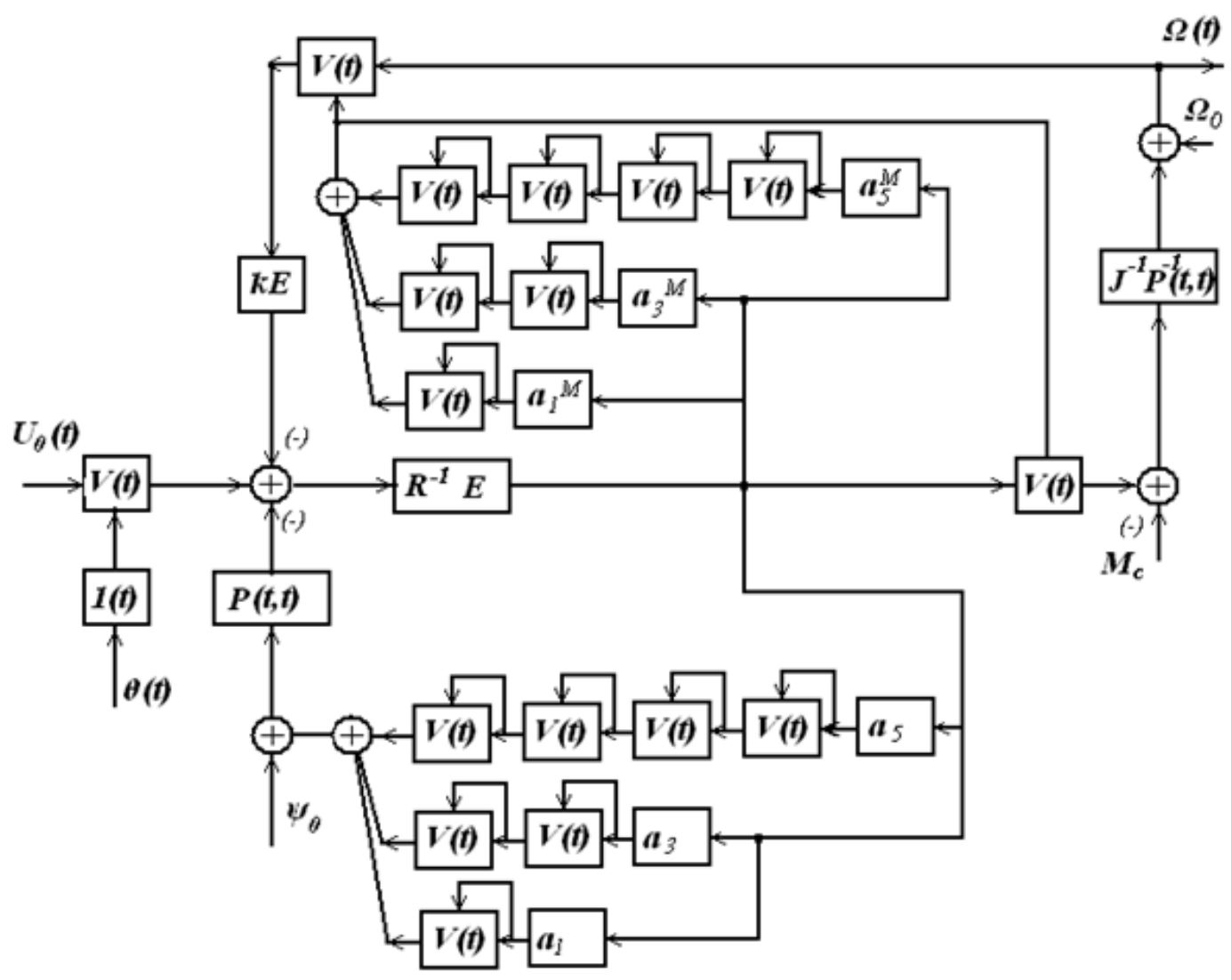

Figure.1. Block diagram of single-phase commutated series-wound motor operated on a converter

The algorithm for the matrix cells calculation should be first built up in the way that the transfer functions could be defined in fixed time interval and then the calculation should be continued with alignment method.

Figure 2 shows the calculation block diagram for nonlinear system built up to find $\Phi_{31}(t, t)$ matrix. This block diagram is presented in the form of the parallel connection of the circuits with $\Phi_{1}\left(h, i_{1}, t\right), \quad \Phi_{2}\left(h, i_{1}, i_{2}, t\right), \quad \Phi_{3}\left(\mathrm{~h}, i_{1}, i_{2}, i_{3}, t\right)$, $\Phi_{4}\left(h, i_{1}, i_{2}, i_{3}, i_{4}, t\right), \quad \Phi_{5}\left(h, i_{1}, i_{2}, i_{3}, i_{4}, i_{5}, t\right)$, $\Phi_{6}\left(h, i_{1}, i_{2}, i_{3}, i_{4}, i_{5}, i_{6}, t\right)$ transfer functions. $C_{1}, C_{2}$ and $C_{3}$ factors are derived from the multi-dimensional unstable transfer function of $\mu(I)$ nonlinear section. Consequently, $\Phi_{31}(t, t)$ defines $I(\tau)$ relationship that has been obtained by summation of all systems responses.

The obtained proportions help to formulate equations that allow to do research of transition processes and quasi-steadystate phenomena in the motor.

$$
\begin{aligned}
& I(t)=\Phi_{31}(t, t) U(t)+\Phi_{32}(t, t) M^{c}(t)+ \\
& +\Omega_{0} \Phi_{34}(t, t) \Delta(t)+\psi_{0} \Phi_{35}(t, t) \Delta(t) \\
& M(t)=\Phi_{21}(t, t) U(t)+\Phi_{22}(t, t) M^{c}(t)+ \\
& +\Omega_{0} \Phi_{24}(t, t) \Delta(t)+\psi_{0} \Phi_{25}(t, t) \Delta(t) \\
& \Omega(t)=\Phi_{11}(t, t) U(t)+\Phi_{12}(t, t) M^{c}(t)+ \\
& +\Omega_{0} \Phi_{14}(t, t) \Delta(t)+\psi_{0} \Phi_{15}(t, t) \Delta(t)
\end{aligned}
$$

Electromagnetic processes, arising within sinusoidal power voltage, are thoroughly studied. It is of great interest to study processes under static converter power supply in order to determine new patterns.

Converter output voltage [2, 24-28]:

$U(\tau, \theta)=U_{m} \sum_{n=0}^{\infty} \sin \left(\tau-\frac{2 \pi n}{m}\right)\left[1\left(\tau-\frac{2 \pi n}{m}-\theta\right)-1\left(\tau-\frac{2 \pi n}{m}-\theta-\lambda_{n}\right)\right]$

where, $U_{m}$ - range of power voltage; $n$ - reference number of valve reckoned from the moment of the first control signal feed; $\theta$ - control angle of $n$ activated valve; $\tau$ - current angular coordinate of the power voltage; $\lambda_{n}$-conductance angle of activated valve; $1(F)$ - unit function equal to 1 when $F>0$, and equal to 0 when $F \leq 0$.

$U(\tau, \theta)$ generalized function can be represented in spectral form by multiplier. One input of multiplier receives continuous signal $U_{m} \sin \left(\tau-\frac{2 \pi n}{m}\right)$. The other input receives pulse sequence $\sum_{n=0}^{\infty} 1(\tau-\theta) . \lambda_{n}$ addend is introduced due to the fact that unstable spectral characteristic of converter output voltage outside unstable interval $t_{n}=\tau-\frac{2 \pi n}{m}-\theta-\lambda_{n}$ is equal to zero. 
The spectral characteristics of multiplier input signals are derived from the following equations:

$$
\begin{aligned}
& B_{c}(t)=S_{c}\left[U_{m} \sin \omega t\right]= \\
& =\left\{\begin{array}{l}
U_{m}(\omega \sqrt{t})^{-1}(\cos \omega t-1), \text { at } i=0 ; \\
U_{m} \omega \sqrt{2 t}\left(i^{2} \pi^{2}-\omega^{2} t^{2}\right)\left[(-1)^{i} \cos \omega t-1\right], \text { at } i=1,2, \ldots,
\end{array}\right. \\
& A_{c}(t)=S_{c}[1(\omega t-\theta)]=\left\{\begin{array}{l}
(t-\theta) \sqrt{\frac{1}{t}}, \text { at } i=0 ; \\
\sqrt{2 t}(i \pi)^{-1} \sin (t-\theta), \text { at } i=1,2, \ldots .
\end{array}\right.
\end{aligned}
$$

In this case the unstable spectral characteristic of converter output voltage is as follows:

$$
U_{c}(t)=\sum_{i} \sum_{k} V_{c c c}(h, i, k, t) A_{c}(k, t) B_{c}(i, t)
$$

The transfer function of the converter, as a section of an automatic control system can be presented by the following equation:

$$
W_{c}^{\text {пр }}(t)=\sum_{k} V_{c c c}(h, i, k, t) A_{c}(k, t) .
$$

Figure 3 shows the calculation algorithm for control system as per "converter-motor" flowchart. The calculation is carried out by means of the alignment method. First, the initial conditions of the system are determined and then their spectral characteristics are obtained on the ground of the basic orthonormal functions system.

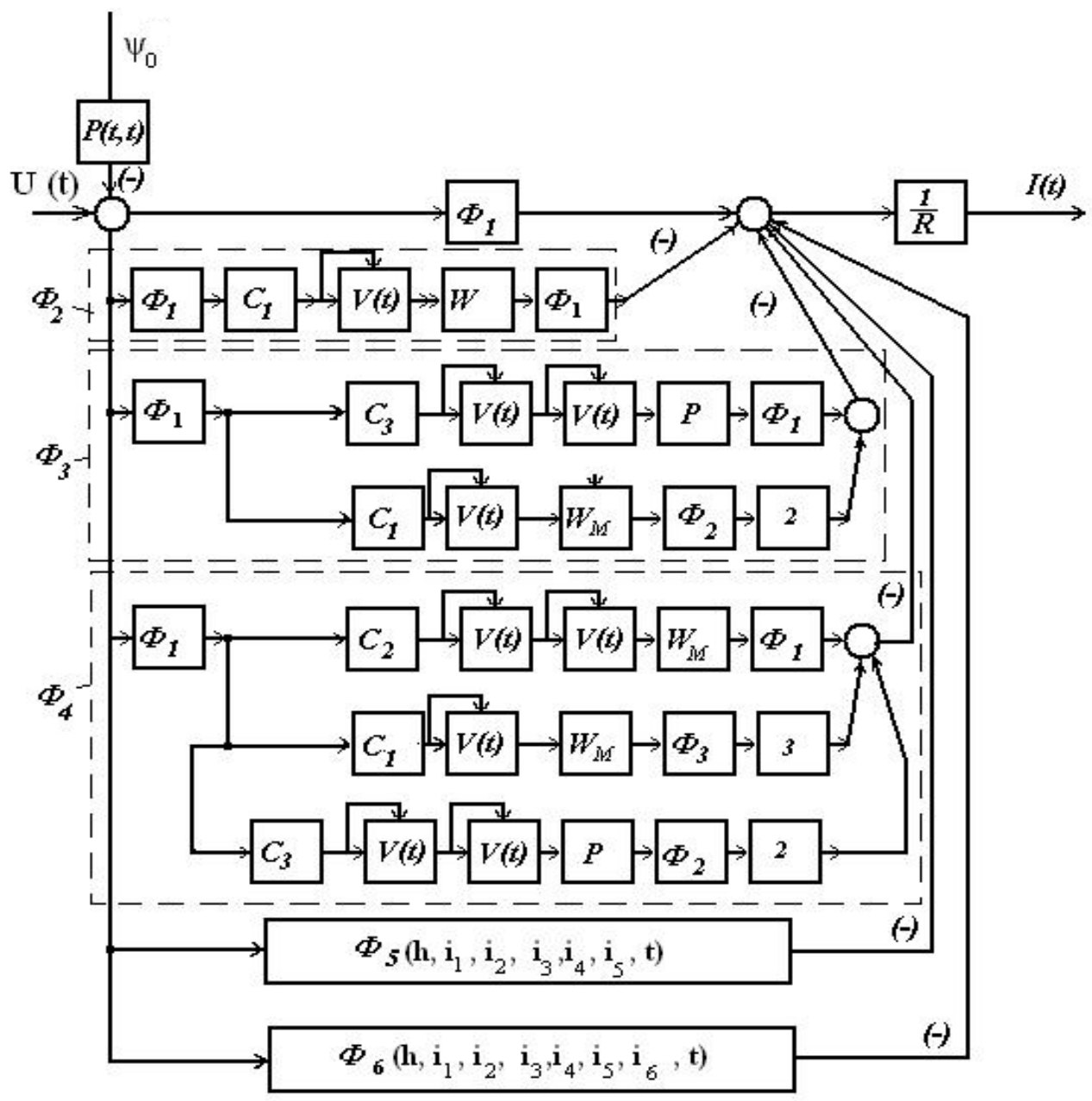

Figure. 2. Calculation block diagram for nonlinear system

The spectral characteristics of other input signals and transfer functions of all system sections are determined in the same way. The calculation of system behavior is carried out within the specified time interval $t_{j}$ provided that the final values of output coordinates of motion are at the same time as the initial values for the following time interval $t_{j+1}$. The same equations are used for calculation. It is only initial conditions of each interval that are different.

\section{Result}

The formulated algorithm is performed in MatLab software that allows studying the joint action of valve-type converter and single-phase commutated series-wound motor. 
The results (fig. $4 \mathrm{a}, 4 \mathrm{~b}$ and $4 \mathrm{c}$ ) show that the conductance time of the valve depends on control angle $\theta$, frequency $\omega$, armature current $I$ and rotation speed $\Omega$. Besides, if the motor rotation speed increases, the time of valve conducting state decreases. The linear relationship of conductance angle of valve, armature current and motor rotation speed proportion at different control angles is detected [6-10]. Figure 5 shows the results of electromagnetic calculations for the system at different converter control angles $\theta$. The obtained relationships of valves conductance angle $\omega t$ at different values of motor rotation speed $\Omega$ and its shaft load can be used in approximate calculations of systems equipped with single-phase commutated series-wound motor. The linear character of the relationships increases their practical relevance.

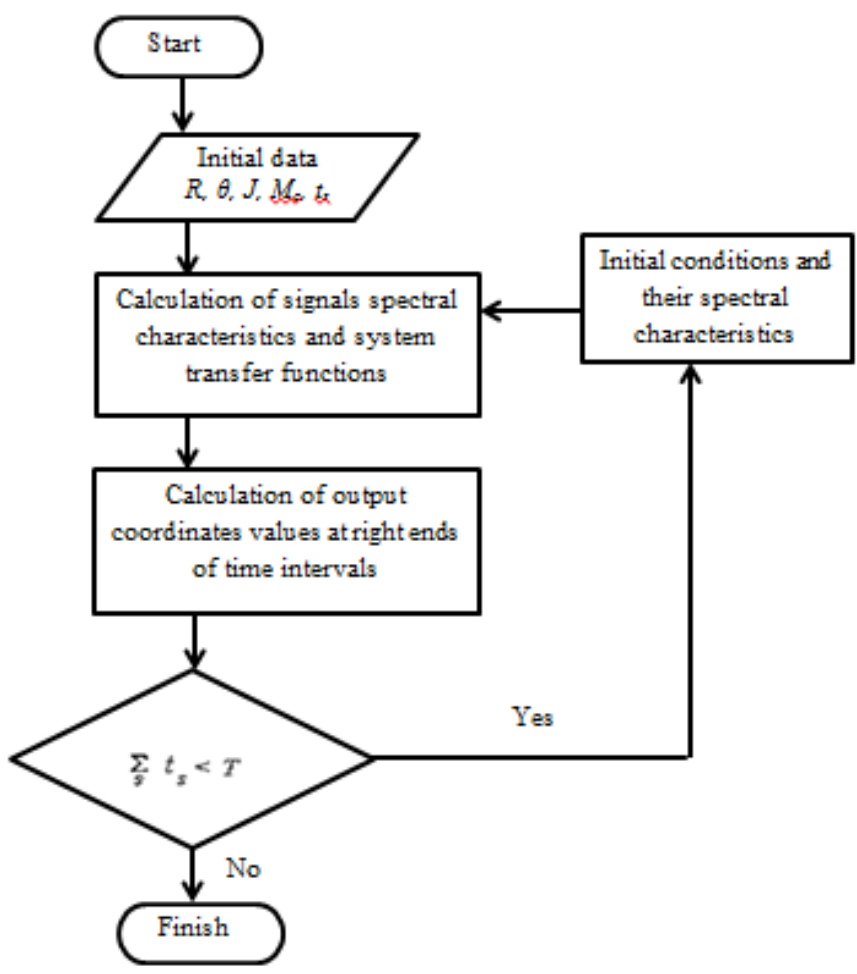

Figure. 3. Algorithms for numerical calculation of electromagnetic processes

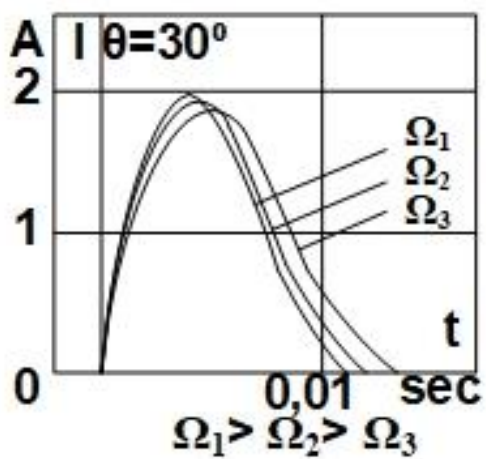

a)

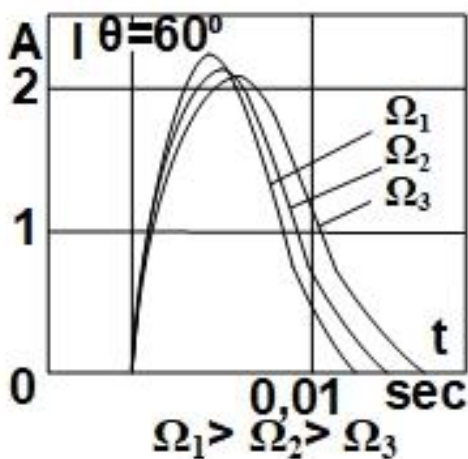

b)

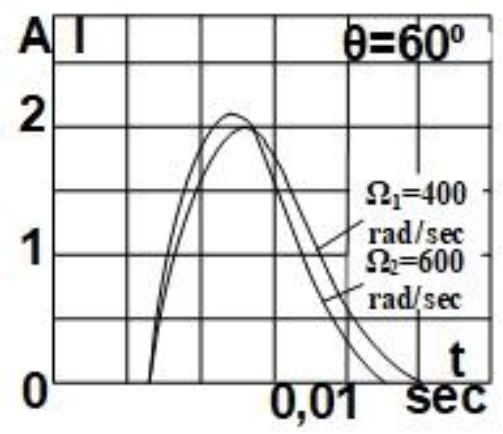

c)

Figure. 4. Dependences of gate current conductivity time of $\theta$ control angle and $\Omega$ rotation velocity: a) $\theta=30^{\circ}$; b) $\theta=60^{\circ}$; c) experimental curves with $\theta=60^{\circ}$ 


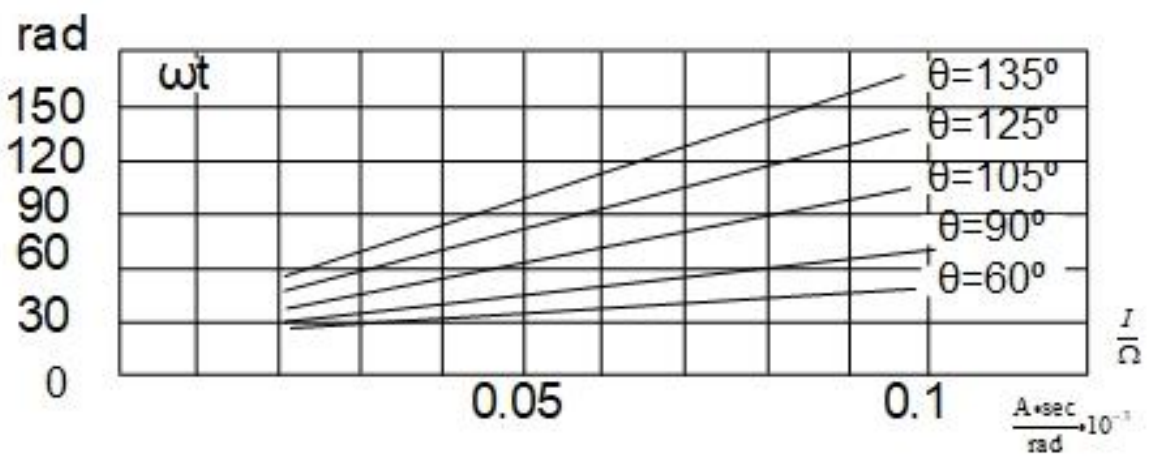

Figure. 5. Dependences of: gate current conductivity angle of armature current to rotation velocity ratio

\section{Discussion}

The undertaken research based on the obtained mathematical model of the single-phase commutated serieswound motor has revealed the reasonable expectation for simulation of the objects under control that differ by the presence of significant nonlinearities of "magnetization curve", "multiplier" type and also the elements with parameters dependent on time, on the basis of the spectral calculation method of the nonlinear unstable systems.

\section{Conclusions}

The proposed methodology of analytical identification of the motions parameters of single-phase commutated serieswound motor shows that the calculation can be carried out only at transient values based on the theory of electromagnetic field.

\section{Acknowledgments}

The research is carried out at Tomsk Polytechnic University within the framework of Tomsk Polytechnic University Competitiveness Enhancement Program.

\section{References}

[1]. Kagan V.G., Lebedev G.V., Malinin L.I. Semiconductorsystems with series motors. Moscow: Energiya, 1971, 96 p. (In Russ.)

[2] Klimov B.P. Thyrystor electric drive with operating series-wound motor, Moscow, Energy Publisher 1972, 87p. (in Russian)

[3]. Bellman M.Kh. Perekhodnye protsessy v mikrodvigatelyakh postoyannogo toka pri impulsnom pitanii [Transients in the DC micro motors with pulse power. Leningrad:Energy, 1975. 134 p. (In Russ.)

[4]. Suzdorf V.I., Kuzmin V.M. (2011), "Mathematical model of independent source with electric machine shaping of output voltage curve", Scientific notes of Komsomolsk-naAmure State Technical University, vol. 1, no. 5, pp. 23-28.

[5]. Dementyev, Y.N., Negodin, K.N., Aung, M.T. Susdorf, V.I. Energy Saving Control of Series Excitation Motor In Package: 4th International Youth Forum on Smart
Grids 2016; Tomsk; Russian Federation; 10 October 2016 through 14 October 2016, MATEC Web of Conferences, Volume 91, 20 December 2016, Article number 01045

[6]. Min Thu Aung, Suzdorf V.I. Dynamic correction of electric drives with series motors. Vestnik Magnitogorskogo Gosudarstvennogo Tekhnicheskogo Universiteta im. G.I. Nosova [Vestnik of Nosov Magnitogorsk State Technical University]. 2018, vol. 16, no. 1, pp. 54-60. https://doi.org/10.18503/1995-2732-2018-16-1-54-60

[7]. Suzdorf V.I., Karpov D.A., (2015), "Energy efficiency of electric hand tools", NEW SCIENCE: THEORETICAL AND PRACTICAL APPROACHES: International scientific serial summarizing the results of the International Workshop (December 14, 2015, Sterlitamak city), in 2 volumes, vol. 1, Sterlitamak: Regional Information Center, International Research Agency, pp. 55 - 57.

[8]. Glazachev, A.V., Dementyev, Y.N., Negodin, K.N., Umursakova, A.D. Mathematical description of an asynchronous motor with the indirect control of the output mechanical variables. MATEC Web Conf. 11001044 (2016)

[9]. Yury Dementyev, Roman Kuzmin, Aleksandr Serikov, Viktor Suzdorf, Kirill Negodin, Istvan Vajda Gearless Micro Hydropower Plant for Small Water-course Acta Polytechnica Hungarica, Volume 14, Issue 4, 2017, Pages 155-166

[10]. Meshkov A.S., Suzdorf V.I., (2014), "Improving energy efficiency of smart household appliances and devices", Journal of Power and Energy Engineering, USA, vol. 2, no. 4, pp. 58-63.

[11]. Meshkov A.S., Suzdorf V.I., Dementyev Y.N., Kaftasyev D.A. (2014), "Energy efficiency improvement of medical electric tools and devices", 1024, The 2nd International Youth Forum "Smart Grids", MATEC Web of Conferences, vol. 19.

[12]. Sami Kanerva. Simulation of electrical machines, circuits and control systems using finite element method and sistem simulator: dissertation for the degree of Doctor of Science in Technology. Helsinki: Helsinki University of Technology, 2005. - 92 p. I

[13]. A Non-a priori Approach to Analyze Electrical Machines Modeled by FEM Connected to Static Converters / A.M. Oliveira, P. Kuo-Peng, N. Sadowski and others. // IEEE Transactions on Magnetics. 2002. - Vol. 38. - No. 2. -P. 933936. 
[14]. A. Gharbi, M. Benrejeb, P, Borne Study of the Stabilization of Uncertain Nonlinear Systems Controlled by State Feedback, Acta Polytechnica Hungarica, vol. 13, no. 4, pp. 21-38, 2016.

[15]. Blaschke F. Das Prinzip der feldorientierung die Grundlage fur die Transvektor - Regelung von Drehfeldmaschinen.//Siemens Zeitschrift, 1971/Bd.45, H.10. - S. 757-760.

[16]. Tishihiko Noguchi, Hiroaki Tomiki, Seiji Kondo and Isao Takahashi, "Direct power control of PWM converters without power-source voltage sensors", IEEE Trans. on Industry Applications, Vol.34. No.3. 1998. pp . 473-479;

[17]. Ivanov, A.G., Belov, G.A., Sergeev, A.G. Control System of Semiconductor Converters, Cheboksary: Chuvash state university Publishing, 2010, 448 p. [in Russian]

[18]. Krause, P.C., Wasynczuk, O., Sudhoff, S.D. (2002) Analysis of Electric Machinery and Drive Systems. IEEE Press

[19]. Kozlov, N., Filipovskii, V.M. Algorithm for controlling coordinated motion of electric drive. Soviet electrical engineering. Volume 60, Issue 6, 1989, Pages 114120

[20]. Mikhov, M., Georgiev, T. An approach to synthesis of a class of electric drives with dual-zone speed control. Advances in Electrical and Computer Engineering. Volume 10, Issue 4, November 2010, Pages 87-94

[21]. Mikhov, M.R., Balev, B.G. Modeling and optimization of an electric drive system with dual-zone speed regulation (2005) Proceedings of International Conference. on Communication and Energy Systems and Technologies, 2, pp. 575-578.

[22]. Semykina I., Zavyalov V., Kashirskikh V. The intelligent mechatronic system for open pit mining to increase the operation life of equipment E3S Web of Conferences. 2017. T. 15. C. 03017.

[23]. Popov A.N. Researches in DC electric drive theory Volume 1,2 Moscow Energoatomizdat 2003, 768p(in Russian)

[24]. Khamitov Rustam, N., Samokhvalova Anastasia, Y. Modeling of DC motor with pulse-duration transducer (2015) 2014 Dynamics of Systems, Mechanisms and Machines, Dynamics 2014 - Proceedings, art. no. 7005658

[25]. Prusova, O.L., Khamitov, R.N. Thermodynamic basics of the pneumatic shock-absorber working (2015) 2014 Dynamics of Systems, Mechanisms and Machines, Dynamics 2014 - Proceedings, art. no. 7005690 ,

[26]. Basharin A.V. Calculation of dynamics and synthesis of non-linear control systems Moscow, Gosenergoizdat Publisher 1960 298p. (in Russian)

[27]. A. Payuk, N. A. Voronina, O. V. Galtseva, Energy

Characteristics of Electric Drive of Oscillatory Motion at the Shock-Free Start Journal of Physics: Conference Series. 2016. — Vol. 671 (1), 012044 DOI: 10.1088/17426596/671/1/012044

[28]. Kashirskikh V.G., Gargayev A.N., Zavyalov V.M., Semykina I.Yu. Computer system for electric drives fault diagnosis of mining shovels. В сборнике: Coal in the 21st Century: Mining, Processing and Safety. 2016. C. 274-279. 